\title{
THE HORNICH-HLAWKA INEQUALITY AND BERNSTEIN FUNCTIONS
}

\section{PAUL RESSEL}

Abstract. The Hornich-Hlawka inequality for three real numbers is extended from the identity function to all Bernstein functions on the half-line. For vectors in a Euclidean space it is shown to hold for the square-root function.

Mathematics subject classification (2010): 26A48, 26 D07.

Keywords and phrases: Hornich-Hlawka inequality, Bernstein function, $n$-alternating function.

\section{REFERENCES}

[1] C. Berg, J. P. R. Christensen And P. Ressel, Harmonic Analysis on Semigroups, SpringerVerlag, New York, 1984.

[2] E. HLawKa, Ungleichungen, Manz-Verlag, Wien, 1990.

[3] H. HoRNich, Eine Ungleichung für Vektorlängen, Math. Zeitschrift, 48 (1942), 268-274.

[4] L. M. Kelly, D. M. Smiley AND M. F. S miley, Two dimensional spaces are quadrilateral spaces, Amer. Math. Monthly, 72 (1965), 753-754.

[5] D. S. Mitrinovic, Analytic Inequalities, Springer-Verlag, New York, 1965.

[6] J. E. Pechić, F. Proschan And Y. L. Tong, Convex Functions, Partial Orderings, and Statistical Applications, Acad. Press, Boston, 1992.

[7] P. RESSEL, Functions operating on multivariate distribution and survival functions - With applications to classical mean-values and to copulas, J. Multivar. Analysis, 105 (2012), 55-67.

[8] R. Schilling, R. Song And Z. VondraČeK, Bernstein Functions, de Gruyter-Verlag, Berlin, 2010.

[9] D. M. Smiley And M. F. Smiley, The polygonal inequalities, Amer. Math. Monthly, 71 (1964), $755-760$.

[10] J. H. Wells And L. R. Williams, Embeddings and Extensions in Analysis, Springer-Verlag, New York, 1975. 